\title{
All types of component malrotation affect the early patient-reported outcome measures after total knee arthroplasty
}

\author{
Mohammad Kamal Abdelnasser ${ }^{1}$, Mohamed Eslam Elsherif ${ }^{1 *}$ (D), Hatem Bakr ${ }^{1}$, Mohamed Mahran ${ }^{1}$, \\ Moustafa H. M. Othman ${ }^{2}$ and Yaser Khalifa ${ }^{1}$
}

\begin{abstract}
Purpose: Outcomes following total knee arthroplasty (TKA), whether clinical, radiological or survival analysis, have been well-studied. Still, there are some concerns about patient satisfaction with the outcome of the surgery and factors that might contribute to a suboptimal result. This study aims to determine if there is correlation between primary TKA malalignment and early patient-reported outcome measures (PROMs).

Materials and methods: Sixty patients, who had primary TKA and a minimum of 2 years of follow up, were recruited for a detailed clinical and radiological examination. Knee alignment was measured in the coronal, sagittal and axial planes. Normal and the outlier measurements of the patients' knees were defined and the clinical results (PROMs) compared to see if there was a statistically significant difference.

Results: Correlation between postoperative limb malalignment in the coronal and the sagittal planes and PROMs was not significant. Conversely, there was significant negative correlation between all types of malrotation and PROMs.

Conclusions: Although malalignment has been linked to inferior outcome and implant survival, our results showed that coronal and sagittal limb malalignment has no significant effect on early PROMs. However, all types of component rotational malalignment significantly worsen early PROMs.
\end{abstract}

Keywords: Knee, Alignment, Arthroplasty, PROMs, Component malrotation

\section{Introduction}

Although total knee arthroplasty (TKA) is a wellestablished orthopedic procedure with documented success; patient dissatisfaction after surgery is still substantially high [1]. Out of each five patients who undergo TKA, one patient is dissatisfied with the results of his or her knee surgery [1]. Outcome after TKA is multifactorial. Patient factors, surgeon factors, implant type, and alignment can influence the outcome after TKA [2].

The real value of patient-reported outcome measures (PROMs) is to have a full view of the patients' functional limitations, pain levels, mental health state, and expectations from their treatment, thus improving communication between surgeons and patients with the potential

\footnotetext{
* Correspondence: m.eslam.elsherif87@gmail.com

Orthopedic Department, Assiut University Hospitals, Assiut, Egypt Full list of author information is available at the end of the article
}

for improving postoperative outcomes. Although clinical and radiological evaluations are vital in reaching the proper diagnosis, PROMs should always be assessed as we are treating patients not the $\mathrm{x}$ rays [3].

The effect of malalignment on the outcome after TKA remains controversial. The majority of authors link malalignment to decreased implant survival $[4,5]$. Others, however, have not noted such correlation [6]. Few researchers $[2,7,8]$ have studied the effect of malalignment on PROMs after TKA. Moreover, most of these reports are based on the outcomes at long-term follow up in terms of implant survival, revision rate, and complications.

Outcomes after total knee arthroplasty (TKA), whether clinical, radiological, or survival analysis, have been well-studied. Still, there are some concerns about patient satisfaction with the outcome of the surgery and factors that might contribute to a suboptimal result. This study aims to determine if there is correlation between

(c) The Author(s). 2019 Open Access This article is distributed under the terms of the Creative Commons Attribution 4.0 International License (http://creativecommons.org/licenses/by/4.0/), which permits unrestricted use, distribution, and reproduction in any medium, provided you give appropriate credit to the original author(s) and the source, provide a link to the Creative Commons license, and indicate if changes were made. The Creative Commons Public Domain Dedication waiver (http://creativecommons.org/publicdomain/zero/1.0/) applies to the data made available in this article, unless otherwise stated. 
primary TKA malalignment and early PROMs. Our hypothesis is that malalignment after primary TKA, especially rotational malalignment, has a direct effect on the early PROMs.

\section{Materials and methods}

This is a retrospective cohort study that included $60 \mathrm{pa}-$ tients with primary TKA (60 TKAs). After searching our Arthroplasty Unit database, we contacted 145 patients who had undergone primary TKA and had a minimum follow-up period of 24 months: 60 patients (about 41\% of those contacted) were available for clinical and radiological examination. Of these, 46 patients were female (77\%) and 14 were male $(23 \%)$. The mean age was $57 \pm$ 9.6 years. The underlying cause of their knee problems was osteoarthritis (49 patients (82\%)) and rheumatoid arthritis (11 patients (18\%)). Patients who had undergone revision TKA, previous knee surgery such as high tibial osteotomy, previous knee trauma, or postoperative complications such as infection and intraoperative complications such as fractures were excluded to avoid confounding bias.

The senior author had performed all surgery in these patients using a medial parapatellar approach. Initially the distal femoral cut was made according to the valgus correction angle (VCA), which was individualized according to the difference between the anatomical and mechanical axis as demonstrated on the full-length radiograph obtained in the weight-bearing position. The inter-epicondylar line was used to define the rotation of the femoral component. The tibial cut was made using the external guide. The tibial component was then rotated to the proper rotation depending on the tibial landmark, which is the medial third of the tibial tubercle. A cemented Nex Gen Legacy posterior stabilized (LPS) flex fixed bearing (Zimmer, Warsaw, IN, USA) was used in all knees. According to our institutional postoperative follow-up protocol, all patients were clinically and radiologically evaluated at 6 weeks and at $3,6,12$, and 24 months.

All 60 patients were recruited for a simultaneous detailed PROMs evaluation and radiological examination including both $\mathrm{x}$-rays and computer tomography $(\mathrm{CT})$ at a minimum of 24 months postoperative follow-up (range 24-132 months postoperative) by an independent researcher in the period from June 2017 to December 2017. Assessments were as follows:

1. Clinical assessment: this was based on the following scores; Knee Society Score (KSS) [9], Knee Osteoarthritis and Disability Outcome Score, Joint replacement (KOOS-Jr) [10, 11], Oxford Knee score (OKS) [12] and Short Form Health Survey (SF-12) [13].
2. Radiological assessment: this was performed as described subsequently.

\section{Coronal limb alignment}

Coronal mechanical alignment of the lower limb was measured by calculating the hip-knee-ankle (HKA) [14, 15] axis angle (Fig. 1), using anterior-posterior-projection, standing position, full-length radiographs of both lower limbs. There is a consensus that postoperative, coronal, limb alignment should be within $0^{\circ} \pm 3^{\circ}$ of the mechanical axis $[6,16]$. Patients with mechanical axis angles outside this range are considered to have coronal limb malalignment (outliers) $[6,16]$.

\section{Sagittal limb alignment}

The anterior cortical line angle [17] was calculated to detect the degree of overall sagittal limb malalignment, by marking the anterior cortical line of the proximal tibia and of the distal femur and measuring the angle between these two lines (Fig. 2) on a lateral-projection radiograph of the knee obtained with the knee in maximal extension. Normal sagittal alignment is defined by hyperextension values between $0^{\circ}$ and $5^{\circ}$. Flexion values $>0^{\circ}$ and hyperextension values $>5^{\circ}$ are defined as flexion and hyperextension outliers, respectively [17].

\section{Component rotational alignment}

We followed the protocol described by Berger et al. [18] to evaluate component rotation. The patient was placed supine on the CT scanning table with the affected limb in full extension and adjusted for acquisition of scans perpendicular to the mechanical axis of the knee. A lateral-projection scout film was acquired to ensure that the CT scans were perpendicular to the long axis of the femur and tibia by tilting the CT gantry accordingly. Imaging slices $1.5 \mathrm{~mm}$ thick were obtained at four locations: through the epicondylar axis on the femur, though the tibial tubercle, through the top of the tibial plateau, and through the tibial component. Measurements were calculated from the axial slices as described subsequently.

\section{Femoral component rotation}

Femoral component rotation was assessed using the axial CT image of the femur at the level of the femoral epicondyles. We used the surgical transepicondylar axis, which is the line connecting the medial epicondylar sulcus to the lateral epicondylar prominence. The posterior condylar line of the femoral component was schemed as a line drawn by connecting the posterior margins of the medial and lateral posterior component condylar surfaces. The angle between these two lines was then measured to obtain the posterior condylar angle (Fig. 3). The femoral component was considered neutral when internally rotated $3.5^{\circ}( \pm 1.2)$ and $0.3^{\circ}( \pm 1.2)$ in relation to the 


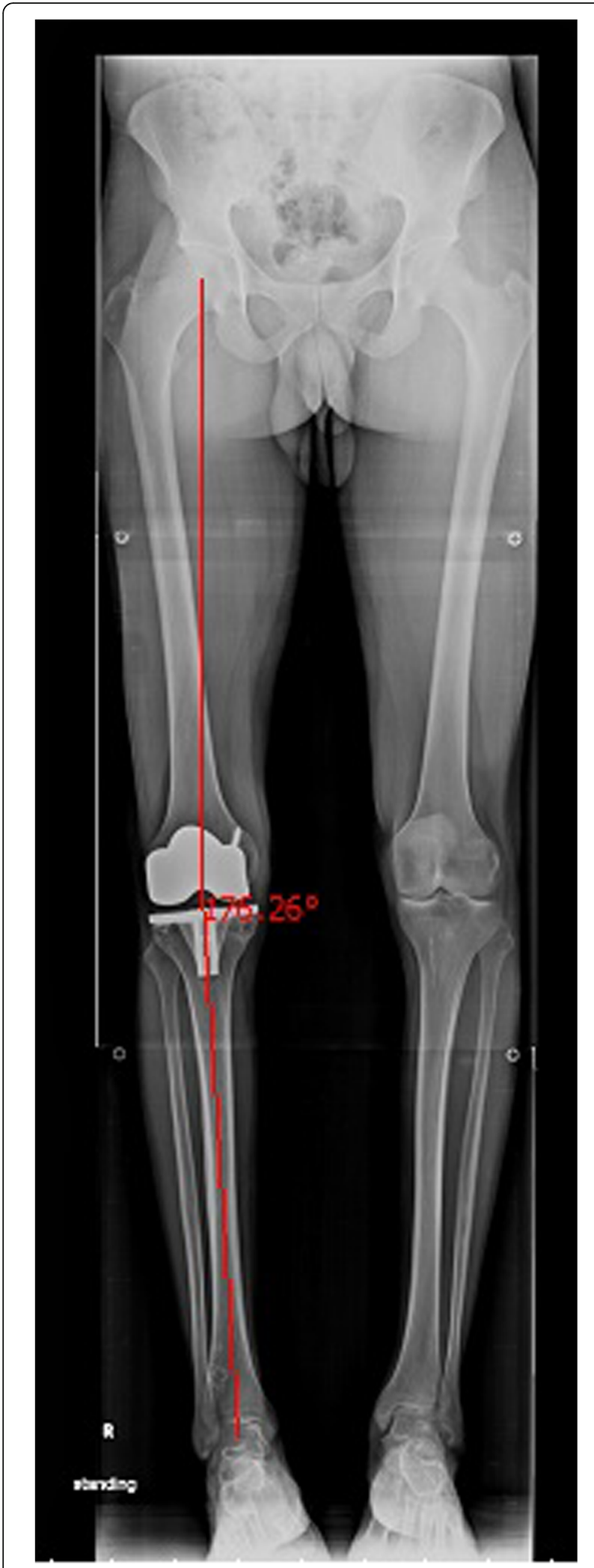

Fig. 1 Full-length, standing-position, anterior-posterior radiograph of both lower limbs showing the hip-knee-ankle (HKA) axis

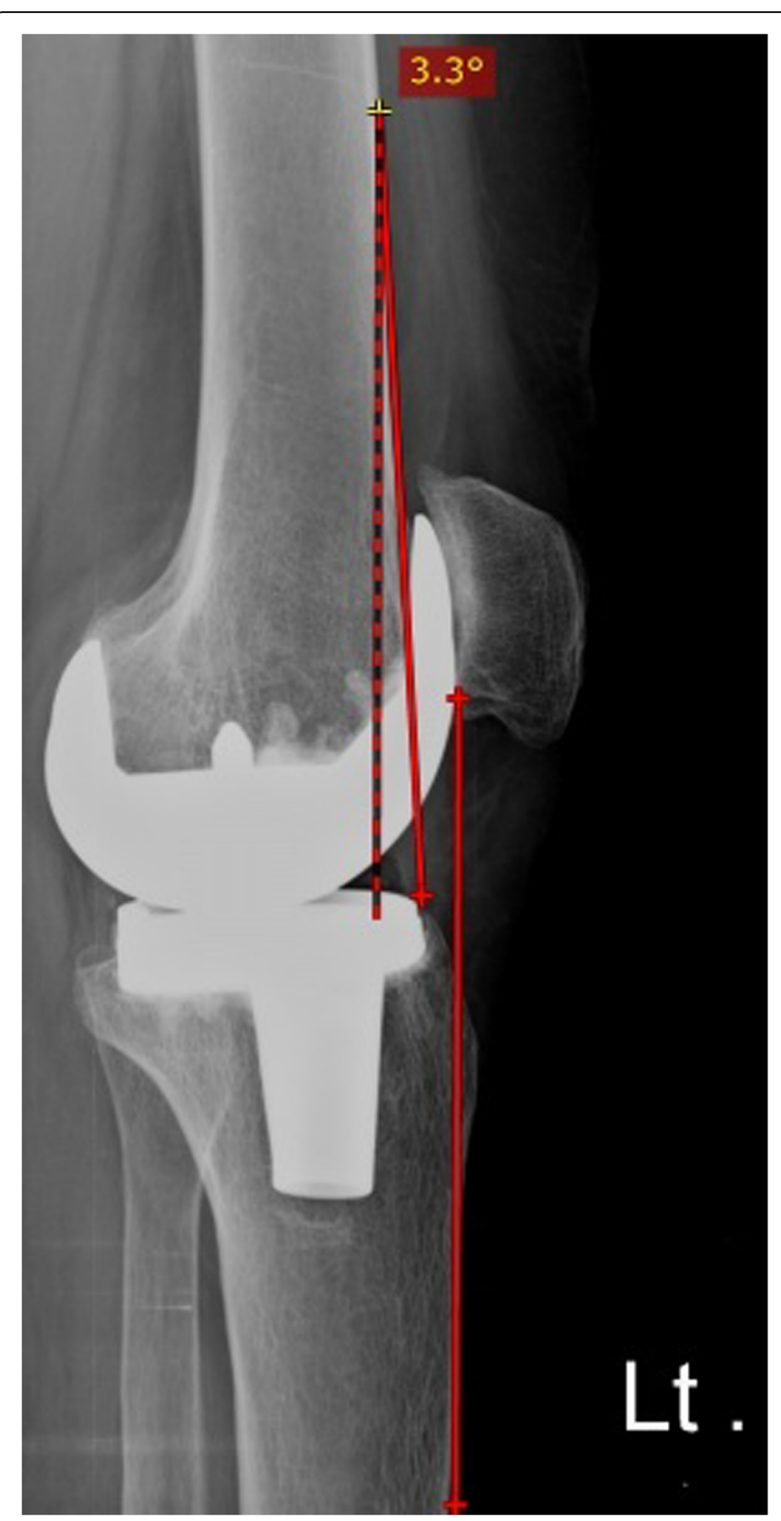

Fig. 2 Lateral-projection radiograph of the knee in maximal extension showing the anterior cortical line angle (sagittal limb alignment) by drawing the anterior cortical line of the proximal tibia and of the distal femur and measuring the angle between these two lines

surgical transepicondylar axis (sTEA) in men and women, respectively [18]: patients with a posterior condylar angle outside this range were considered to have femoral component rotational malalignment (outliers) $[18,19]$.

\section{Tibial component rotation}

Tibial component rotation was assessed from three axial CT images through the tibia. The geometric center of the tibial plateau was located from an axial image just below the tibial component. The geometric center is axially transposed to an axial image through the prominence of the tibial tuberosity and a line is drawn from the 


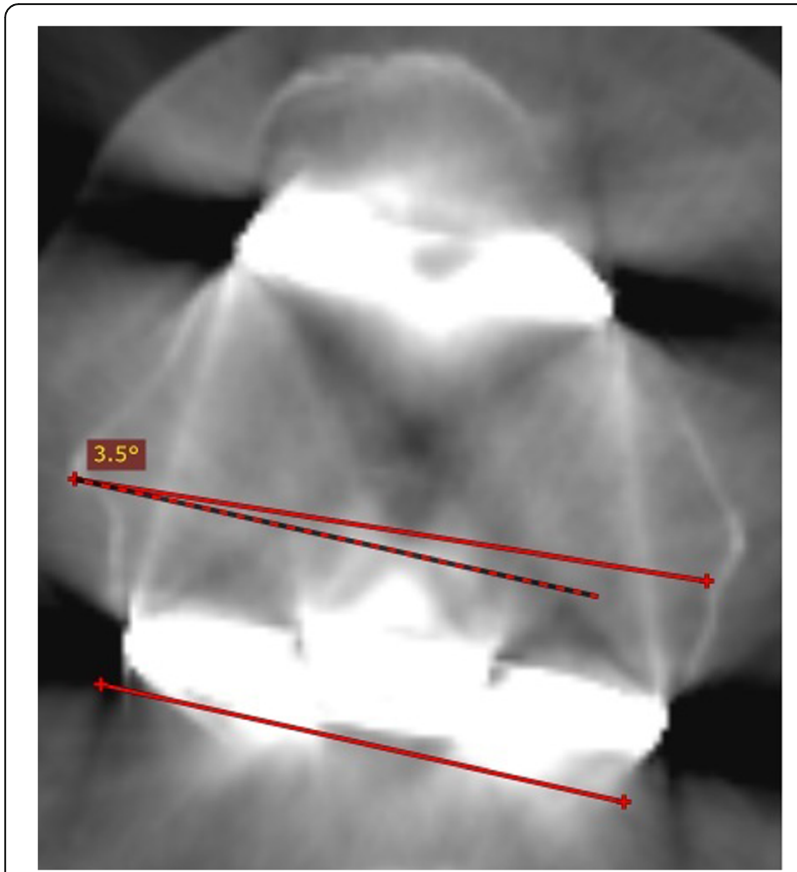

Fig. 3 Axial computed tomography slice of a total knee arthroplasty in a male patient, showing neutral femoral component rotation in relation to the surgical transepicondylar axis (STEA). The sTEA is plotted as a line drawn from the sulcus of the medial epicondyle to the prominence of the lateral epicondyle. The posterior condylar line of the femoral component is plotted as a line drawn from connecting the posterior margins of the medial and lateral posterior component condylar surfaces. The angle between these two lines was then measured and is the posterior condylar angle

geometric center and the tuberosity, the tibial tuberosity axis. The tibial component axis was drawn at the level of the component polyethylene as a line perpendicular to a line drawn along the posterior surface of the component polyethylene. The tibial tuberosity axis was then axially transposed to this image and the angle between these two lines was measured (Fig. 4).
The relationship between the tibial tubercle and tibial articular surface was used to assess tibial component rotation, whether internally or externally rotated. The tip of the tibial tubercle is $18^{\circ}$ externally rotated from the tibial articular surface. The tibial component was considered neutral in both men and women when internally rotated $18^{\circ}( \pm 2.6)$ in relation to the tip of the tibial tuberosity [18]: patients with an angle this range are considered to have tibial component rotational malalignment (outliers) [18].

\section{Combined rotation}

Combined component rotation was measured by adding together the femoral and tibial component rotation angles.

\section{Rotation mismatch}

Component mismatch was calculated by subtracting femoral from tibial component rotation.

Statistical analysis Data were verified, coded, and analyzed using SPSS version 21 (IBM Corp, Armonk NY, USA). Descriptive statistics (mean, standard deviation, median and percentage) were calculated. Statistical significance was tested using the independent $t$ test to compare the means of dichotomous variables, and analysis of variance (ANOVA) to compare the means of variables with more than two categories. Correlation was tested to determine the association between variables (Spearman's rank correlation). A $p$ value equal to or less than 0.05 was considered significant.

\section{Results}

Sixty patients were eligible for our study. Limb alignment was assessed in the coronal plane: optimum coronal limb alignment $\left( \pm 3^{\circ}\right)$ was identified in 39 TKAs $(65 \%)$, with outliers identified in 21 TKAs (35\%) (19 varus TKAs and 2 valgus TKAs). In the sagittal plane, 15 TKAs (25\%) were

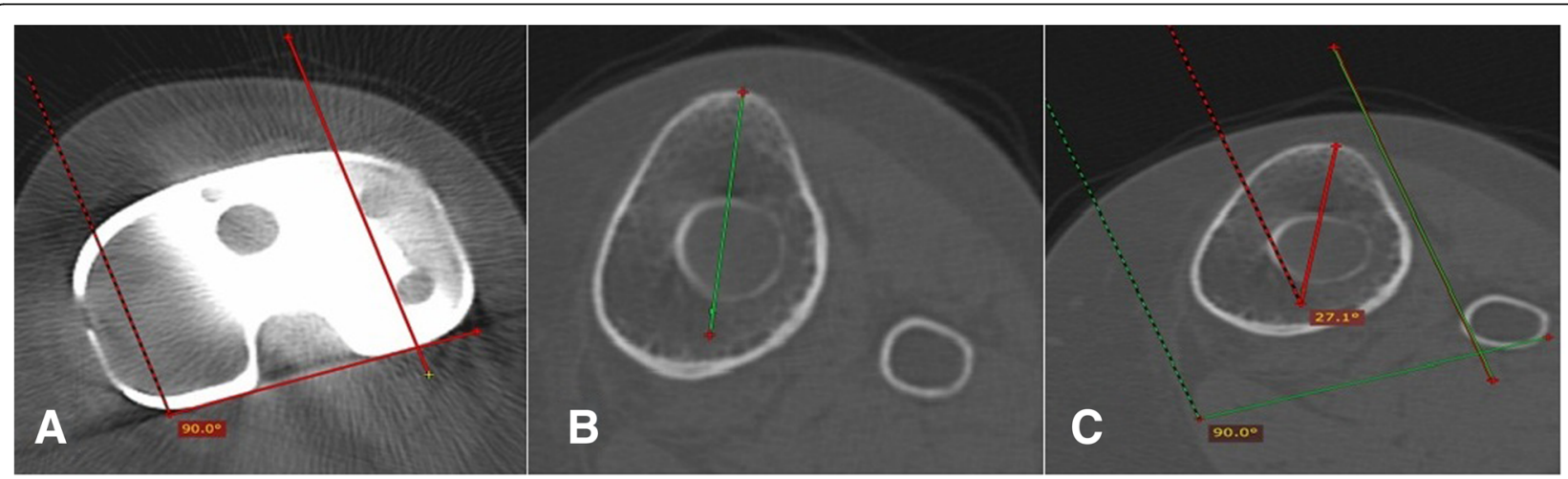

Fig. 4 a Axial computed tomography $(C T)$ image through the tibial component polyethylene showing the tibial component axis, which is defined as the perpendicular to the posterior margin of the component. b Axial CT image through the tibial tuberosity showing the tibial tuberosity axis (T.T.A), which is defined by the line connecting the geometric center of the tibial plateau to the tip of the tibial tubercle. c The T.T.A from $\mathbf{b}$ is superimposed on the tibial component axis (T.C.A) from $\mathbf{a}$. The rotation of the tibial component is recorded as the angle subtended by the T.T,A and the T.C.A 
found to have optimum sagittal limb alignment $\left(0-5^{\circ}\right)$ and 45 TKAs were considered outliers. Hyperextension was identified in 31 (51.7\%) TKAs and flexion deformity was identified in 14 (23.3\%) TKAs.

In the assessment of component alignment in the axial plane, optimum femoral component rotation $\left(3.5^{\circ}\right.$ and $0.3^{\circ} \pm 1.2$ in relation to sTEA in men and women respectively) was identified in 16 TKAs (26.7\%) and 44 TKAs were considered outliers; there were 16 (26.7\%) TKAs with an internally rotated and 28 (46.6\%) with an externally rotated femoral component. Optimum tibial component rotation $\left(18^{\circ} \pm 2.6\right.$ internal rotation in relation to the tibial tuberosity axis in both men and women) was identified in 28 TKAs (46.6\%) and 32 TKAs were considered outliers; there were $22(36.6 \%)$ TKAs with an internally rotated and $10(16.8 \%)$ with an externally rotated tibial component. Furthermore, combined component rotation (5 with combined internal rotation and 10 with combined external rotation) was identified in 15 (25\%) TKAs and component rotation mismatch was identified in 17 (28.3\%) TKAs. Table 1 summarizes normal alignment and outliers in the sagittal, coronal, and axial planes in the cohort studied.

Correlation between postoperative limb malalignment in the coronal plane and the sagittal planes and patients' satisfaction scores was negative and minimal, and was not statistically significant.

Table 1 Results of normal alignment and outliers in the sagittal, coronal, and axial planes in the studied cohort ( $n=60$ patients)

\begin{tabular}{|c|c|c|c|}
\hline Variable & Category & $\begin{array}{l}\text { Number } \\
\text { (percentage) }\end{array}$ & Mean \pm SD \\
\hline \multirow{3}{*}{$\begin{array}{l}\text { Postoperative coronal } \\
\text { limb alignment }\end{array}$} & Normal & $39(65 \%)$ & $-0.34 \pm 0.3$ \\
\hline & Varus outliers & $19(30 \%)$ & $6.74 \pm 0.5$ \\
\hline & Valgus outliers & $2(5 \%)$ & $5.83 \pm 0.6$ \\
\hline \multirow{3}{*}{$\begin{array}{l}\text { Postoperative sagittal } \\
\text { limb alignment }\end{array}$} & Normal & $15(25 \%)$ & $2.32 \pm 0.3$ \\
\hline & $\begin{array}{l}\text { Hyperextension } \\
\text { outliers }\end{array}$ & $31(51.7 \%)$ & $14.97 \pm 1.9$ \\
\hline & Flexion outliers & $14(23.3 \%)$ & $7.23 \pm 1.1$ \\
\hline \multirow{3}{*}{$\begin{array}{l}\text { Femoral component } \\
\text { rotation }\end{array}$} & Normal & $16(26.7 \%)$ & $3.21 \pm 0.2$ \\
\hline & $\begin{array}{l}\text { Internal Rotation } \\
\text { outliers }\end{array}$ & $16(26.7 \%)$ & $-0.86 \pm 0.2$ \\
\hline & $\begin{array}{l}\text { External Rotation } \\
\text { outliers }\end{array}$ & $28(46.6 \%)$ & $1.55 \pm 0.4$ \\
\hline \multirow{3}{*}{$\begin{array}{l}\text { Tibial component } \\
\text { rotation }\end{array}$} & Normal & $28(46.6 \%)$ & $0.04 \pm 0.01$ \\
\hline & $\begin{array}{l}\text { Internal Rotation } \\
\text { outliers }\end{array}$ & $22(36.6 \%)$ & $-6.22 \pm 0.7$ \\
\hline & $\begin{array}{l}\text { External Rotation } \\
\text { outliers }\end{array}$ & $10(16.8 \%)$ & $6.44 \pm 1.4$ \\
\hline Rotation mismatch & & 17 & $9.31 \pm 1.9$ \\
\hline \multirow[t]{2}{*}{ Combined rotation } & Internal Rotation & 5 & $-7.42 \pm 1.1$ \\
\hline & External Rotation & 10 & $9.43 \pm 1.5$ \\
\hline
\end{tabular}

Conversely, there was significant moderate negative correlation between femoral component malrotation (internal or external) and all patient satisfaction scores. The correlation coefficient $(r)$ was -0.55 ( $p$ value $<0.0001)$, 0.58 ( $p$ value $<0.0001),-0.062$ ( $p$ value $<0.0001)$, 0.59 ( $p$ value $<0.0001$ ) for KSS, KOOS-JR, OKS, and SF-12 scores, respectively (Figs. 5 and 6). Additionally, there was significant, weak, negative correlation between tibial component malrotation and KOOS-Jr and SF-12 scores. The correlation coefficient $(r)$ was -0.23 ( $p$ value $<$ $0.041)$ and -0.33 ( $p$ value $<0.005)$ for KOOS-JR and SF-12 scores, respectively (Figs. 7 and 8). Also, there was a significant, moderate, negative correlation with component rotation mismatch (Fig. 9). The correlation coefficient $(r)$ was -0.47 ( $p$ value $<0.001)$ and $-0.49(p$ value $<0.022)$ for KSS and SF-12 scores, respectively. Furthermore, there was significant, moderate, negative correlation with combined component rotation (Fig. 10). The correlation coefficient ( $r$ ) was -0.48 ( $p$ value $<0.035)$ for KOOS-JR (Table 2 ).

Mean satisfaction scores for normal alignment and outliers were compared using the $t$ test, and there was no significant difference between the two groups in coronal and sagittal alignment. However, there was a significant difference in the case of rotational malalignment of the femur and tibia (Table 3).

Mean satisfaction scores were significantly different in ANOVA in cases of combined rotation or rotational mismatch compared to cases of normal rotation (Table 4).

\section{Discussion}

The most important finding of the present study was that we did not identify correlation between limb malalignment in the coronal and sagittal planes and the patientreported outcome measures, namely KSS, KOOS-Jr, Oxford knee score, and SF-12, after a minimum of 2 years follow up. Conversely, there was positive correlation with all rotational malalignment (femoral malrotation, tibial malrotation, combined rotation, and rotation mismatch) after a minimum of 2 years follow up.

At a minimum of 1 year follow up, Longstaff et al. [7] showed that good alignment can lead to better function, with quicker rehabilitation and earlier hospital discharge. Bach et al. [8], on the other hand, found no correlation between implant alignment and patient quality of life. In a randomized controlled trial, Choong et al. [2] compared alignment between computer-assisted surgery (CAS) and conventional TKA. Neutral mechanical alignment was achieved in CAS more than in conventional TKA. Moreover, there was significant, positive correlation between accurate mechanical alignment after TKA and functional and quality-of-life patient outcomes. At 6 weeks postoperatively, the International Knee Society (IKS) score was significantly better in patients with a mechanical axis within $3^{\circ}$ of neutral than when compared to those patients 


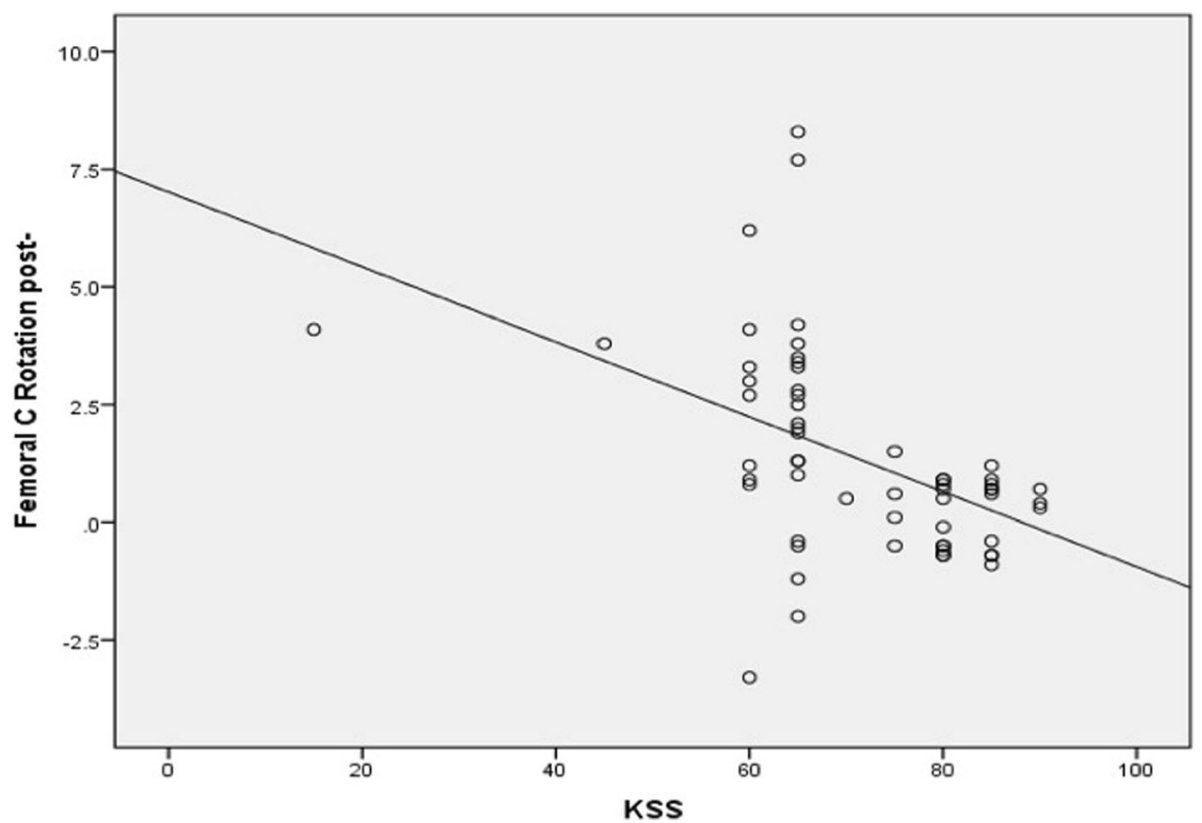

Fig. 5 Correlation between femoral component rotation postoperative and the Knee Society Score (KSS)

with greater than $3^{\circ}$ from neutral, and these results were sustained at all follow-up intervals up until the end of follow up at 12 months. The physical component of the SF-12 scores at the 3-month, 6-month, and 12-month reviews was also significantly better in the group with good alignment.

Blakeney et al. [20] prospectively studied a cohort of 107 patients who underwent TKA. At a mean of 46 months follow up, there was a clinically significant difference in the functional scores in patients treated with CAS versus those treated conventionally. A significant improvement in the OKS was noted when the mechanical axis was within $\pm 3^{\circ}$ of neutral, whether navigated or not, versus outliers.

Also, Huang et al. [21] showed that accurate coronal alignment of a total knee prosthesis (to within $3^{\circ}$ of

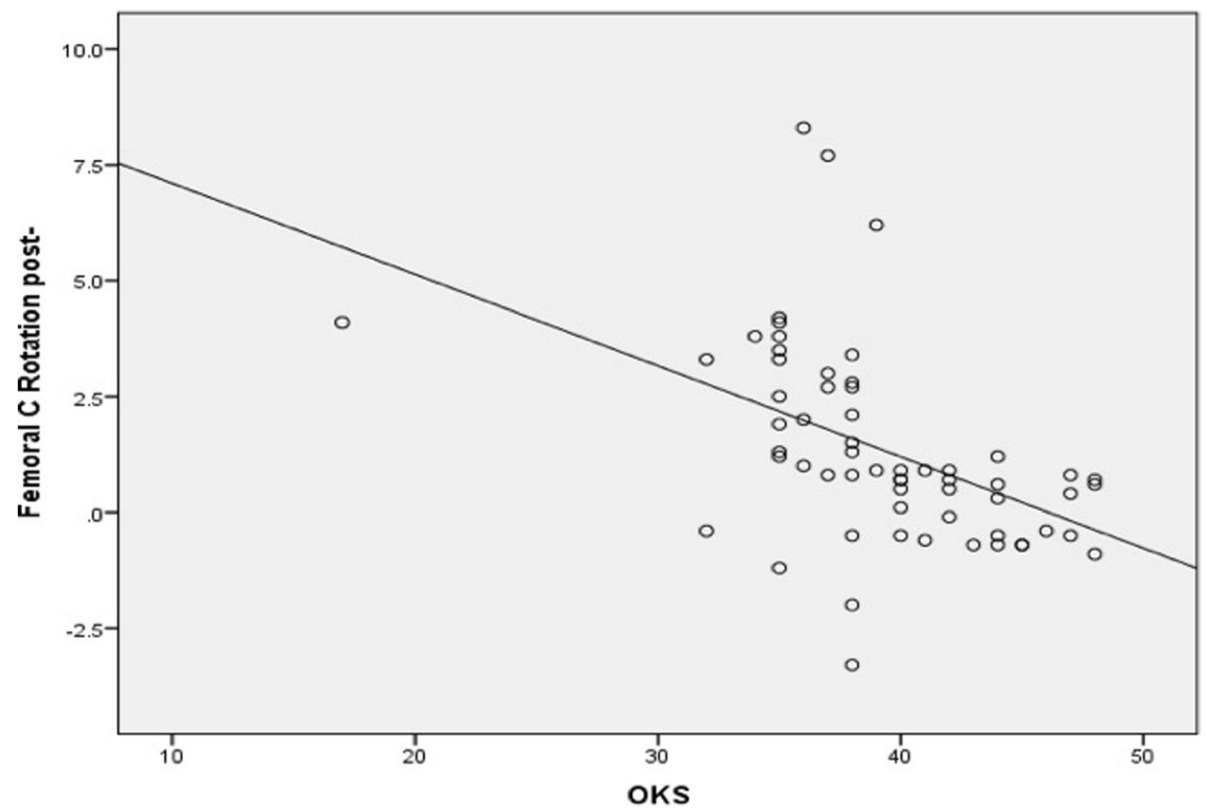

Fig. 6 Correlation between femoral component rotation postoperative and the Oxford Knee Score (OKS) 


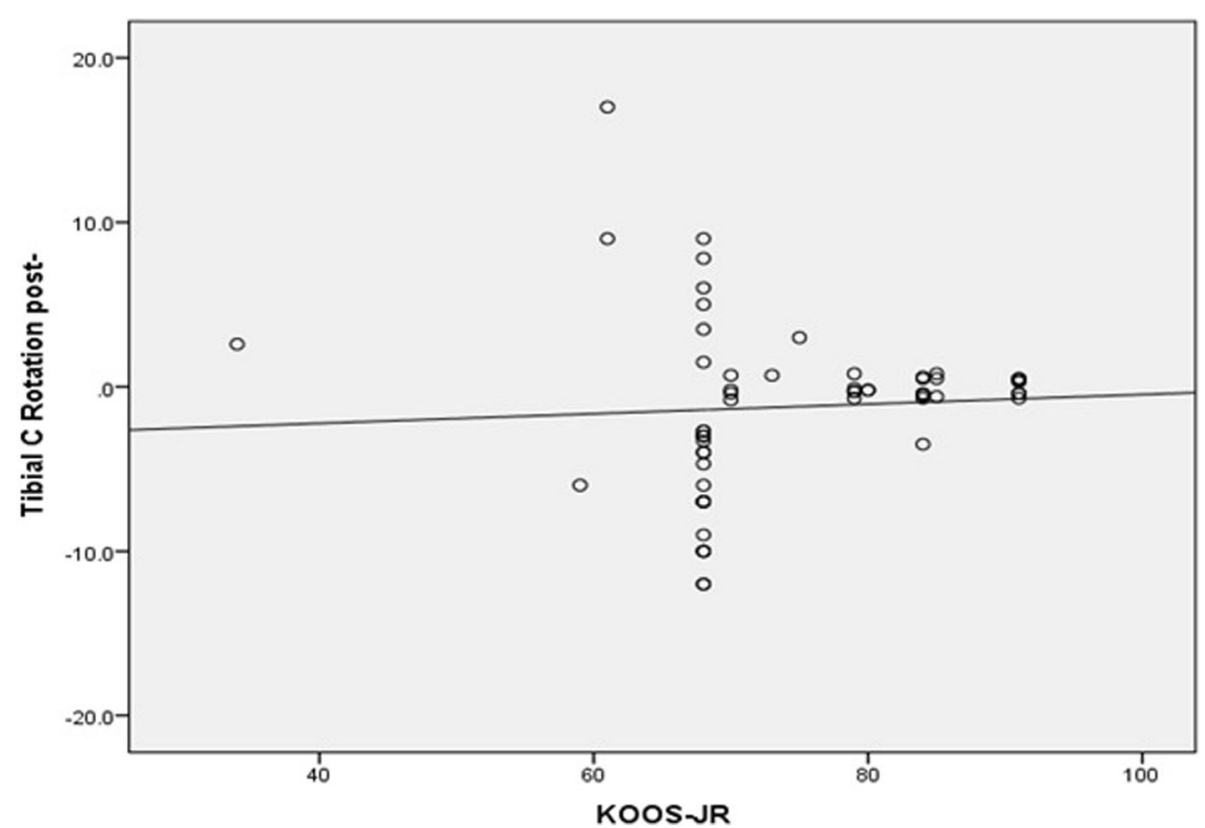

Fig. 7 Correlation between Tibial component rotation postoperative and the Knee Disability and Osteoarthritis Outcome Score, Joint replacement (KOOS-JR)

neutral) results in better function and better quality of life up to 5 years postoperatively. They compared patients who achieved postoperative alignment within $3^{\circ}$ of neutral to those with alignments greater than $3^{\circ}$ from neutral, regardless of surgical technique, i.e. CAS versus conventional TKA. The KSS and SF-12 were recorded at 6 weeks, 3 months, 6 months, 12 months, 24 months, and 5 years.
Improved pain scores were seen in accurately aligned prostheses up to 2 years postoperatively; however, this did not continue to 5 years.

Contradicting these results, Stucinskas et al. [22] investigated the effect of coronal alignment on muscle strength and function, including 91 TKAs. Range of motion, KSS, and muscle strength measurements were taken at 1 year.

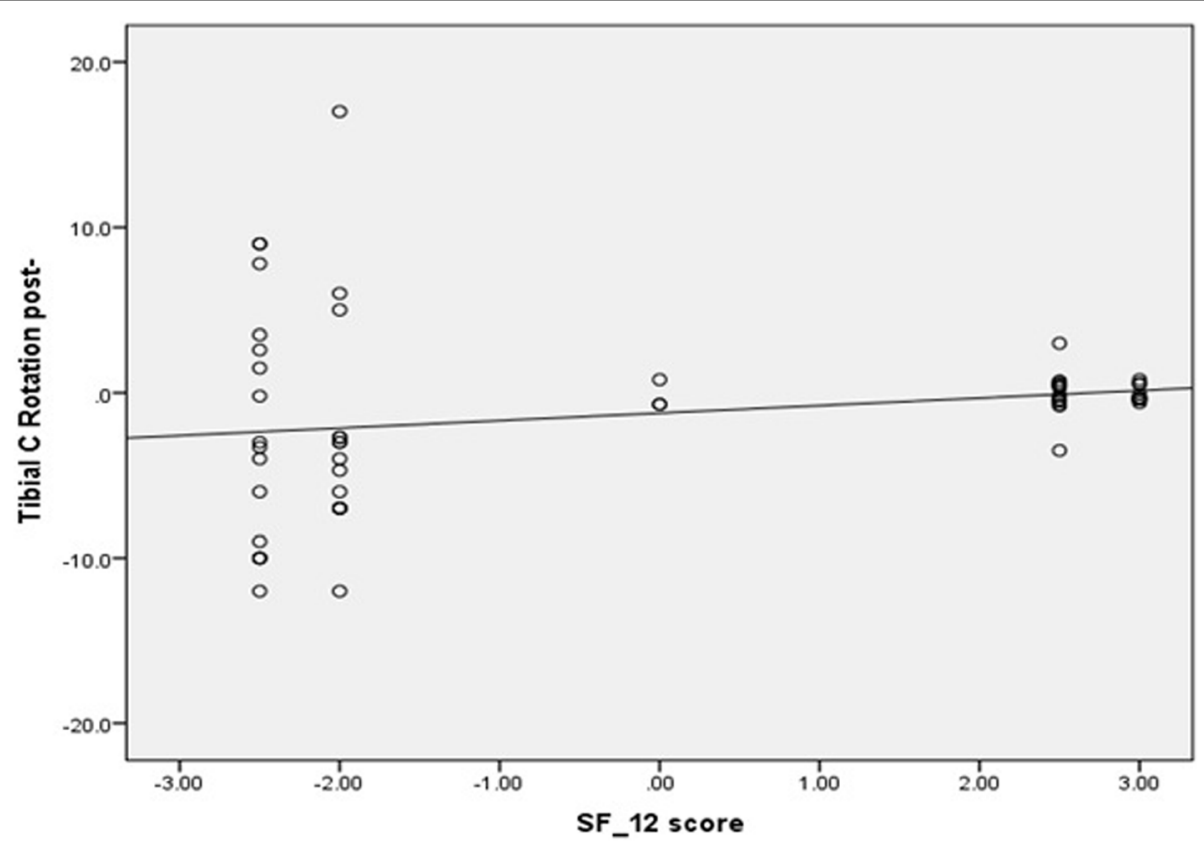

Fig. 8 Correlation between Tibial component rotation postoperative and the Short Form Health Survey-12 (SF-12) score 


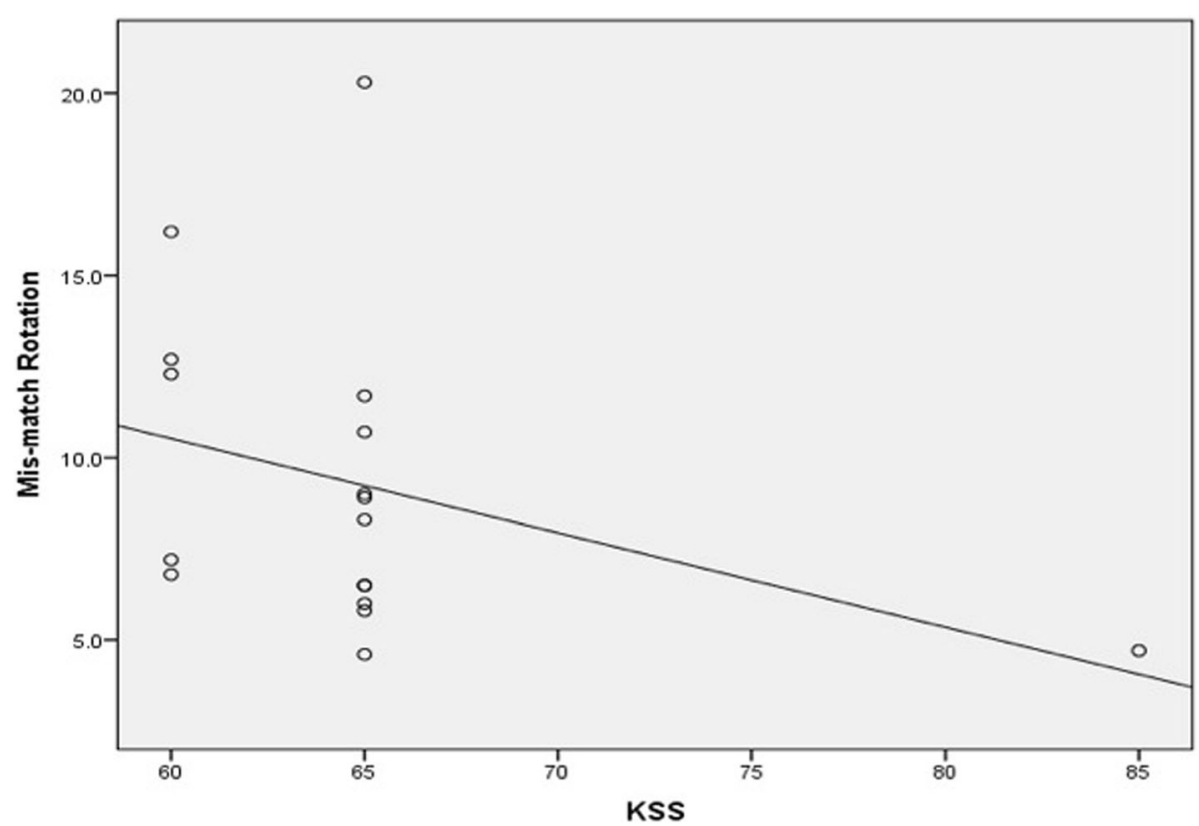

Fig. 9 Correlation between degree of rotation mismatch and the Knee Society Score (KSS)

They found that moderate varus/valgus malalignment of the mechanical axis, or of individual components, has no relevant clinical effect on function or muscle strength 1 year after TKA. Their rationale is that muscles can adapt to a malaligned axis or components without loss of strength, and can also produce function similar to that in normally aligned TKAs.
Matziolis et al. [23], in a case-control study, compared a group with varus maligned TKA and a control group with well-aligned TKA in patients matched for age, sex, and type of prosthesis. The KSS, Western Ontario and McMaster Universities Osteoarthritis Index (WOMAC), and SF-36 were applied. At a minimum of 5 years follow up, there was no statistically

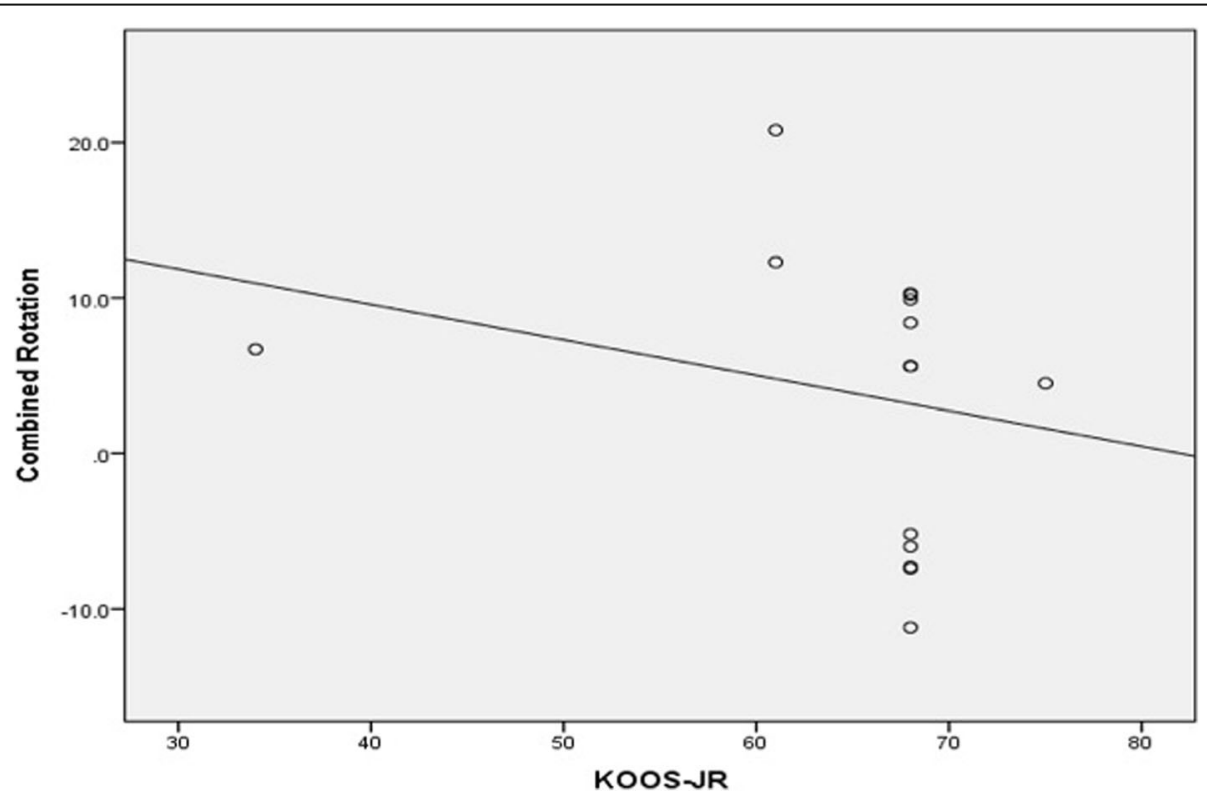

Fig. 10 Correlation between degree of combined rotation and the Knee Disability and Osteoarthritis Outcome Score, Joint replacement (KOOS-JR) 
Table 2 Correlation between patients' satisfaction scores and malalignment angle

\begin{tabular}{|c|c|c|c|c|}
\hline & KSS & KOOS-Jr & OKS & SF-12 \\
\hline & \multicolumn{4}{|c|}{ Correlation coefficient $(r)$ and $p$ value } \\
\hline $\begin{array}{l}\text { Postoperative coronal } \\
\text { limb malalignment }\end{array}$ & $-0.14(>0.05)$ & $-0.17(>0.05)$ & $-0.15(>0.05)$ & $-0.13(>0.05)$ \\
\hline $\begin{array}{l}\text { Postoperative sagittal } \\
\text { limb malalignment }\end{array}$ & $-0.02(>0.05)$ & $-0.06(>0.05)$ & $-0.01(>0.05)$ & $-0.13(>0.05)$ \\
\hline Femoral component malrotation & $-0.55(<0.001)$ & $-0.58(<0.001)$ & $-0.62(<0.001)$ & $-0.59(<0.001)$ \\
\hline Tibial component malrotation & $0.20(=0.059)$ & $-0.23(=0.041)$ & $0.18(=0.086)$ & $-0.33(=0.005)$ \\
\hline Rotation mismatch & $-0.47(<0.001)$ & $-0.21(=0.209)$ & $0.03(>0.05)$ & $-0.49(=0.022)$ \\
\hline Combined rotation & $0.39(=0.077)$ & $-0.48(=0.035)$ & $0.22(>0.05)$ & $0.12(>0.05)$ \\
\hline
\end{tabular}

KSS Knee Society Score, KOOS-Jr Knee Disability and Osteoarthritis Outcome Score, Joint replacement, OKS Oxford Knee Score, SF-12 Short Form Health Survey-12 $P$ value $<0.05$ is significant for those data in bold

significant correlation between the radiological and clinical data.

Similar to our results, all other reports that studied sagittal component alignment failed to identify correlation between implant malalignemt in the sagittal plane and patient outcome $[7,8]$.

As regards component rotation, several authors [24-27] have linked component rotational malalignment with inferior clinical and functional outcomes.

Czurda et al. [28] observed a significant association between the risk of postoperative pain and incorrect rotational alignment of the femoral component. In a casecontrol study, they compared a group of patients with painful TKA and an asymptomatic control group. There was no significant difference between the two groups in mechanical axis, flexion of the femoral component, the dorsal slope, or patella-tracking disorder. However, there was sevenfold elevation in the risk of postoperative pain in those patients with incorrect rotational alignment of the femoral component. Similarly,
Barrak et al. [24] found a significant difference between patients with anterior knee pain and an asymptomatic control group in terms of tibial and combined component rotation. Patients with combined component internal rotation have a fivefold increase in the likelihood of experiencing anterior knee pain following TKA compared with those with combined component external rotation. Bell et al. [29] identified excessive malrotation as an important factor in unexplained pain after TKA. On the other hand, excessive external rotation was not found to be a factor in pain following TKR. They identified internal rotation greater than $3.9^{\circ}$ femoral internal rotation, $5.8^{\circ}$ tibial internal rotation, $8.7^{\circ}$ combined component rotation, and $5.8^{\circ}$ component mismatch to be excessively rotated. Nicoll et al. [25] found that excessive internal rotation of the tibial component $\left(9^{\circ}\right)$ is a major cause of pain after TKR, whereas external rotation of the tibial component was well-tolerated by most patients. Berger et al. [18], in their series, found that excessive combined internal rotation with angles of more

Table 3 Relationship between malalignment and patients' satisfaction scores

\begin{tabular}{|c|c|c|c|c|c|}
\hline Variable & Category & KSS score & KOOS-JR score & OKS score & SF-12 \\
\hline \multirow[t]{3}{*}{ Coronal } & - Normal & $70.90 \pm 12.7$ & $74.03 \pm 10.7$ & $38.95 \pm 5.4$ & $31.64 \pm 2.5$ \\
\hline & - Outliers & $71.67 \pm 13.3$ & $74.24 \pm 10.3$ & $39.71 \pm 4.8$ & $31.14 \pm 2.5$ \\
\hline & $P$ value* & $=0.829$ & $=0.940$ & $=0.575$ & $=0.541$ \\
\hline \multirow[t]{3}{*}{ Sagittal } & - Normal & $71.33 \pm 9.9$ & $74.40 \pm 9.1$ & $40.20 \pm 4.3$ & $31.00 \pm 2.5$ \\
\hline & - Outliers & $71.11 \pm 13.7$ & $74.00 \pm 10.9$ & $38.89 \pm 5.4$ & $31.56 \pm 2.6$ \\
\hline & $P$ value* & $=0.946$ & $=0.890$ & $=0.346$ & $=0.464$ \\
\hline \multirow[t]{3}{*}{ Axial Femur } & • Normal & $78.91 \pm 8.5$ & $80.50 \pm 8.1$ & $42.19 \pm 3.9$ & $33.22 \pm 1.8$ \\
\hline & - Outliers & $62.32 \pm 11.2$ & $66.79 \pm 7.7$ & $35.82 \pm 4.3$ & $29.36 \pm 1.3$ \\
\hline & $P$ value* & $<0.001$ & $<0.001$ & $<0.001$ & $<0.001$ \\
\hline \multirow[t]{3}{*}{ Axial Tibia } & • Normal & $81.25 \pm 5.7$ & $82.29 \pm 7.0$ & $43.00 \pm 3.2$ & $33.82 \pm 0.9$ \\
\hline & - Outliers & $62.34 \pm 10.5$ & $66.94 \pm 7.2$ & $35.91 \pm 4.1$ & $29.31 \pm 1.2$ \\
\hline & $P$ value* & $<0.001$ & $<0.001$ & $<0.001$ & $<0.001$ \\
\hline
\end{tabular}

KSS Knee Society Score, KOOS-Jr Knee Disability and Osteoarthritis Outcome Score, Joint replacement, OKS Oxford Knee Score, SF-12 Short Form Health Survey-12 *The $t$ test was used to compare the mean difference between the two groups

$P$ value $<0.05$ is significant for those data in bold 
Table 4 Relationship between normal rotation, combined rotation, mismatch, and patients' satisfaction scores

\begin{tabular}{lllll}
\hline Scores $($ mean \pm SD) & Normal rotation $(n=28)$ & Mismatch $(n=17)$ & Combined $(n=15)$ & $P$ value* \\
\hline KSS & $81.25 \pm 5.7$ & $64.71 \pm 5.7$ & $59.67 \pm 3.6$ & $<.001$ \\
KOOS-JR & $82.29 \pm 7.1$ & $68.41 \pm 4.6$ & $65.27 \pm 2.8$ & $<0.001$ \\
OKS & $43.00 \pm 3.2$ & $36.88 \pm 2.3$ & $34.80 \pm 5.4$ & $<0.001$ \\
SF-12 & $33.82 \pm 0.9$ & $29.29 \pm 1.2$ & $29.33 \pm 1.3$ & $<0.001$ \\
\hline
\end{tabular}

KSS Knee Society Score, KOOS-Jr Knee Disability and Osteoarthritis Outcome Score, Joint replacement, OKS Oxford Knee Score, SF-12 Short Form Health Survey-12 *Analysis of variance was used to compare the mean difference between groups

$P$ value $<0.05$ is significant for those data in bold

than $7^{\circ}$ or $8^{\circ}$ resulted in more severe patellofemoral complications, whereas combined external rotation did not.

Also, Lutzner et al. [26] studied 73 patients at an average of 20 months after TKA and found that patients with a postoperative rotational mismatch of more than $10^{\circ}$ between the femoral and tibial components showed no improvement and had significantly worse results in the KSS.

Keeping the component rotational mismatch within $\pm 5^{\circ}$ during TKA is needed for controlled knee axial rotation during flexion. Mismatch above or below this range results in measurable kinematic differences and causes different patterns of axial rotation motions during passive knee flexion [27].

Although the average amount of internal rotation of the femoral component in our study was $0.86 \pm 0.2^{\circ}$, which is far below the average in the aforementioned studies, it was significantly associated with worse functional outcome. On the other hand, the average for internal rotation of the tibial component, combined internal rotation, and mismatch was $6.22 \pm 0.7^{\circ}, 7.42 \pm$ $1.1^{\circ}$, and $9.31 \pm 1.9^{\circ}$, respectively, and these values are close to the average values for malrotation in the same studies.

The results of this study confirm that malalignment in the coronal and sagittal plane has no effect on PROMs at short-term follow up, a finding supported by many authors. It seems that muscles adapt to longstanding deformity in the way that it can easily become accustomed to residual deformity after TKA. Component rotational malalignment alters patellofemoral and knee flexionextension kinematics from the first day postoperative. This explains the high incidence of early pain and inferior outcome measures when component malrotation is evident.

The main limitation to this study is the short followup period. A prospective study design with a longer follow-up period will be needed to track the changes in the PROMs and determine whether or not these changes persist in the midterm and long-term follow up. Another important limitation to this study is that there are many other confounding variables such as body mass index (BMI) and psychological factors, etc., which may affect the outcome after TKA.

\section{Conclusions}

Although malalignment has been linked to inferior outcome and implant survival, our results showed that coronal and sagittal limb malalignment has no significant effect on early PROMs. However, all types of component rotational malalignment significantly worsen early PROMs.

\section{Abbreviations}

ANOVA: Analysis of variance; BMI: Body mass index; CAS: Computer assisted surgery; CT: Computerized tomography; HKA: Hip-knee-ankle axis; IKS: International Knee Society score; KOOS-Jr: The Knee Disability and Osteoarthritis Outcome Score, Joint replacement; KSS: Knee Society Score; OKS: Oxford Knee score; Plain A-P: Anteroposterior x-ray view;

PROMs: Patient-reported outcome measures; SF-12: Short Form Health Survey-12; SF-36: Short Form Health Survey-36; sTEA: Surgical transepicondylar axis; TKA: Total knee arthroplasty; VCA: Valgus correction angle; WOMAC: The Western Ontario and McMaster Universities

Osteoarthritis Index

\section{Acknowledgements}

Not applicable.

\section{Authors' contributions}

All authors contributed equally to the manuscript. MKA and MEE generated the concept, literature search, manuscript preparation, and reviewing; MM and $\mathrm{HB}$ contributed by defining the intellectual content, literature search, manuscript preparation and editing; MHMO and YK contributed by manuscript editing and reviewing. All authors read and approved the final manuscript.

\section{Funding}

All authors disclose any financial and personal relationships with other people or organizations that could inappropriately influence this study.

\section{Availability of data and materials}

The datasets obtained and/or analyzed during the current study are available from the corresponding author on reasonable request.

\section{Ethics approval and consent to participate}

Informed consent was obtained from the patients following the guidelines set forth by our institution and by the Declaration of Helsinki and Good Clinical Practice. The consent included approval from the patient that they would undergo radiography and $\mathrm{CT}$ at follow up. This study was approved by the institutional review board of our institution.

\section{Consent for publication}

Each author certifies that he has participated sufficiently in the preparation of this article and has read and agrees with the contents of the manuscript. Each author further represents that the article is original, that it is not under consideration by another journal, and that it has not been previously published. In consideration of the Knee Surgery \& Related Research reviewing and editing our submission, the authors undersigned hereby transfer, assign, and otherwise convey all copyright ownership to Knee Surgery \& Related Research, and represent that they own all rights in the material submitted. This assignment is to take effect only if the work is published in the journal. 


\section{Competing interests}

The authors declare that they have no competing interests.

\section{Author details}

'Orthopedic Department, Assiut University Hospitals, Assiut, Egypt.

${ }^{2}$ Radiology Department, Assiut University Hospitals, Assiut, Egypt.

Received: 19 May 2019 Accepted: 11 June 2019

Published online: 05 July 2019

\section{References}

1. Bourne RB, Chesworth BM, Davis AM, Mahomed NN, Charron KD (2010) Patient satisfaction after total knee arthroplasty: who is satisfied and who is not? Clin Orthop Relat Res 468(1):57-63

2. Choong PF, Dowsey MM, Stoney JD (2009) Does accurate anatomical alignment result in better function and quality of life? Comparing conventional and computer-assisted total knee arthroplasty. J Arthroplast 24(4):560-569

3. Lyman S, Yin KL (2017) Patient-reported outcome measurement for patients with total knee arthroplasty. J Am Acad Orthop Surg 25(Suppl 1):S44-s47

4. Fang DM, Ritter MA, Davis KE (2009) Coronal alignment in total knee arthroplasty: just how important is it? J Arthroplast 24(6 Suppl):39-43

5. Ritter MA, Faris PM, Keating EM, Meding JB (1994) Postoperative alignment of total knee replacement. Its effect on survival. Clin Orthop Relat Res 299:153-156

6. Parratte S, Pagnano MW, Trousdale RT, Berry DJ (2010) Effect of postoperative mechanical axis alignment on the fifteen-year survival of modern, cemented total knee replacements. J Bone Joint Surg Am 92(12): 2143-2149

7. Longstaff LM, Sloan K, Stamp N, Scaddan M, Beaver R (2009) Good alignment after total knee arthroplasty leads to faster rehabilitation and better function. J Arthroplast 24(4):570-578

8. Bach CM, Mayr E, Liebensteiner M, Gstottner M, Nogler M, Thaler M (2009) Correlation between radiographic assessment and quality of life after total knee arthroplasty. Knee 16(3):207-210

9. Insall JN, Dorr LD, Scott RD, Scott WN (1989) Rationale of the Knee Society clinical rating system. Clin Orthop Relat Res 248:13-14

10. Lyman S, Lee YY, Franklin PD, Li W, Mayman DJ, Padgett DE (2016) Validation of the HOOS, JR: a short-form hip replacement survey. Clin Orthop Relat Res 474(6):1472-1482

11. Almangoush A, Herrington L, Attia I, Jones R, Aldawoudy A, Abdul Aziz A et al (2013) Cross-cultural adaptation, reliability, internal consistency and validation of the Arabic version of the knee injury and osteoarthritis outcome score (KOOS) for Egyptian people with knee injuries. Osteoarthr Cartil 21(12):1855-1864

12. Alghadir AH, Al-Eisa ES, Anwer S (2017) Cross-cultural adaptation and psychometric analysis of the Arabic version of the oxford knee score in adult male with knee osteoarthritis. BMC Musculoskelet Disord 18(1):190

13. Obtel M, El Rhazi K, Elhold S, Benjelloune M, Gnatiuc L, Nejjari C (2013) Cross-cultural adaptation of the 12-Item Short-Form survey instrument in a Moroccan representative survey. South Afr J Epidemiol Infect 28(3):166-171

14. Moreland JR, Bassett LW, Hanker GJ (1987) Radiographic analysis of the axial alignment of the lower extremity. J Bone Joint Surg Am 69(5):745-749

15. Cooke TD, Sled EA, Scudamore RA (2007) Frontal plane knee alignment: a call for standardized measurement. J Rheumatol 34(9):1796-1801

16. Bonner TJ, Eardley WG, Patterson P, Gregg PJ (2011) The effect of postoperative mechanical axis alignment on the survival of primary total knee replacements after a follow-up of 15 years. J Bone Joint Surg Br. 93(9):1217-1222

17. Paley D (2002) Principles of deformity correction, 1st edn. Springer, New York, p 161

18. Berger R, Crossett L, Jacobs J, Rubash H (1998) Malrotation causing patellofemoral complications after total knee arthroplasty. Clin Orthop Relat Res 356:144-153

19. Berger RA, Rubash HE, Seel MJ, Thompson WH, Crossett LS (1993) Determining the rotational alignment of the femoral component in total knee arthroplasty using the epicondylar axis. Clin Orthop Relat Res 286:40-47

20. Blakeney WG, Khan RJ, Palmer JL (2014) Functional outcomes following total knee arthroplasty: a randomised trial comparing computer-assisted surgery with conventional techniques. Knee 21(2):364-368
21. Huang NF, Dowsey MM, Ee E, Stoney JD, Babazadeh S, Choong PF (2012) Coronal alignment correlates with outcome after total knee arthroplasty: five-year follow-up of a randomized controlled trial. J Arthroplasty 27(9): 1737-1741

22. Stucinskas J, Robertsson O, Sirka A, Lebedev A, Wingstrand H, Tarasevicius S (2015) Moderate varus/valgus malalignment after total knee arthroplasty has little effect on knee function or muscle strength. Acta Orthop 86(6):728-733

23. Matziolis G, Adam J, Perka C (2010) Varus malalignment has no influence on clinical outcome in midterm follow-up after total knee replacement. Arch Orthop Trauma Surg 130(12):1487-1491

24. Barrack RL, Schrader T, Bertot AJ, Wolfe MW, Myers L (2001) Component rotation and anterior knee pain after total knee arthroplasty. Clin Orthop Relat Res 392:46-55

25. Nicoll D, Rowley DI (2010) Internal rotational error of the tibial component is a major cause of pain after total knee replacement. J Bone Joint Surg Br 92(9):1238-1244

26. Lutzner J, Gunther KP, Kirschner S (2010) Functional outcome after computer-assisted versus conventional total knee arthroplasty: a randomized controlled study. Knee Surg Sports Traumatol Arthrosc 18(10): 1339-1344

27. Harman MK, Banks SA, Kirschner S, Lutzner J (2012) Prosthesis alignment affects axial rotation motion after total knee replacement: a prospective in vivo study combining computed tomography and fluoroscopic evaluations. BMC Musculoskelet Disord 13:206

28. Czurda T, Fennema P, Baumgartner M, Ritschl P (2010) The association between component malalignment and post-operative pain following navigation-assisted total knee arthroplasty: results of a cohort/nested casecontrol study. Knee Surg Sports Traumatol Arthrosc 18(7):863-869

29. Bell SW, Young P, Drury C, Smith J, Anthony I, Jones B et al (2014) Component rotational alignment in unexplained painful primary total knee arthroplasty. Knee 21(1):272-277

\section{Publisher's Note}

Springer Nature remains neutral with regard to jurisdictional claims in published maps and institutional affiliations.
Ready to submit your research? Choose BMC and benefit from:

- fast, convenient online submission

- thorough peer review by experienced researchers in your field

- rapid publication on acceptance

- support for research data, including large and complex data types

- gold Open Access which fosters wider collaboration and increased citations

- maximum visibility for your research: over $100 \mathrm{M}$ website views per year

At BMC, research is always in progress.

Learn more biomedcentral.com/submissions 